\title{
Serious Fraud, Long Trials and Criminal Justice
}

\author{
The Hon. Mr. Fustice Henry*
}

The list of those who have given this lecture before me is daunting in its distinction. There you will find the great names of our law, judges, jurists, and philosophers. To hear them speak on any topic was to be enlightened and enriched, and so they were invited to talk on any topic of their choice.

My invitation was not so couched. Here the subject was chosen, rather than the speaker. I was asked because of my practical experience. I have, first as an advocate and then as a judge, had some experience of long trials: to this fact alone I owe the honour of this invitation.

So while in previous lectures in this series you have been addressed, to use a military metaphor, by the staff officers with their Olympian vision, this is the view from the front line, from the immediacy of the trenches. This inevitably may result in some loss of detachment or perspective, but if the fight against over-long trials is to be won, it has to be won at trial. The appeal is too late.

And it is fitting that Child's Bank should, through you, have extended this invitation to me, because my first experience of a trial lasting more than 100 days was for their then parent. It was a civil case. It lasted, including vacations, 9 months. A director of the bank, who had been responsible for the conduct of the account in question, was examined in the witness box for 6 weeks. The time there spent added little to what was plain to be seen on the contemporary documents. The Bank won (using that term in its narrow legal sense, and paying no regard to the Pyrrhic element of that victory, the cost to be counted in the final balance sheet after having taken into account not only any shortfall between legal entitlement and actual recovery, but also the indirect costs of personnel being kept from their real duties during the trial). However the Bank was good enough to invite me to a dinner to celebrate the victory. When called on to speak, I questioned the cause for celebration. The legal result reached was one that should have been reached in a fraction of the time. Whoever was the winner, it did not seem to me to be the system, nor, would I have thought, the parties who had been through it. And that was a civil trial, where the problems of reducing length are not as acute as in criminal trials.

* The Child \& Co. Lecture 1991, London, published by arrangement with the Hon. Mr. Justice Henry and Child \& Co. 
Those problems in criminal trials are intractable. They are universal wherever the criminal adversarial system is practised. And nowhere within that system have they been solved. This is because the problems are the product of the adversarial system itself. Accordingly they will not be solved without alteration to that system. Yet that system is regarded, and rightly so, as an important protection of the individual and his civil liberties. That system is all of a piece. So any alteration to that system will bring with it a potential civil liberties penalty, and must be critically examined on that basis.

Here I will try to give them the trial judge's perspective on the problems as they exist, and how they might be reduced. But there are no easy answers. If there were someone would have come up with them by now.

No-one can doubt the importance of the subject. The competence of the criminal law to deal with serious fraud is clearly crucial to-day when the powerdriven, greed-fed dishonest excesses of the 80 's have not proved to be the end of an unfortunate era, but an introduction to worse since.

We have to be able to deal with serious fraud: to deter it, to detect it, and to punish it. We must do this to protect the creditors, employees and shareholders of limited liability companies. We must do this to protect the public, whose pensions and insurances depend on it. We must do this to protect the integrity of the market. If the market is not seen to be honest and transparent, investors will go elsewhere. And if they do, so that money cannot be readily raised on the market, companies will have to raise money at greater expense elsewhere. So prices will go up. And if investors prefer the markets of our international competitors, so the country will suffer internationally as well as domestically.

It is essential that the criminal law plays its part in this. The siren song of decriminalisation and the fallacies of the so called victimless crime must be rejected. There must be the same justice for white collar fraud as for blue collar fraud, the same for the rich as for the poor. And the sentences for dishonesty must be effective and equivalent in both cases. In both cases the powers to prosecute may and will be used selectively, but used they must be, and used against the prime movers.

In the short space of this lecture I deal only with the criminal trial itself. I do not deal with deterrence, or substantive changes in the law, or the question of the end of self-regulation and the introduction of an equivalent body to the SEC.

Our specification for our criminal justice system is that it must be effective in convicting the guilty and acquitting those not proved to be so. It must be as accurate as a system depending on human input at all levels can be. It must be fair but inevitable. It must be no respecter of persons, so it must be more powerful than the most powerful. And it must not be wasteful of money, because the public is paying for it, nor wasteful of time - because time wasted in one case leads to delay in the hearing of another, and, budgets being finite, resources exhausted in one trial cannot be used in another.

Some serious fraud trials satisfy those criteria, others most certainly do not. Of 
the latter, the following criticisms can be made. They take too long. They are open-ended as to time and cost. They are insufficiently focused on the real issues. They cost too much. They happen too late. Such trials are not satisfactory for anyone, not the jury, not for the defence, not for the prosecution, and not for the cause of justice. And in the resulting situation, the public sees the process as being unable to cope, and suspects that it is being too easily manipulated or frustrated by the rich and powerful.

This problem is not restricted to this country. In the common law world, wherever the adversarial system obtains, the problems are the same and no solution has yet been found: all suffer from mega-trials, and all agree as to how unsatisfactory such trials are. But no-one has yet found the answer.

Here, after the Roskill reforms (which I shall deal with later) the hope was that after definition of the issues and a realistic appreciation of the facts in the preparatory hearing, there would be served up to the jury only what Lord Devlin described as "the big questions", the crucial questions of fact and (classically in these cases) the central and dominant question of honesty. But that hope has yet to be fulfilled. The post-Roskill experience in this country is that the length of the jury portion of criminal trials of serious fraud has taken between seven and 18 months, and in most of those cases the trial judge has used his powers of severance to reduce one mega-trial to two or more smaller trials. Such trials followed lengthy preparatory hearings. This time bracket is also typical for comparable trials in other common law jurisdictions such as America and Canada. But it is disappointing.

I believe that current trial lengths are longer than are necessary or useful to enable the jury to give their best answer to those big questions. I believe that view to be common among judges with experience of comparable trials. I believe that in all but the quite exceptional case, the jury's best answer to these big questions will not turn on more fine detail than can properly be examined in, say, a four month jury trial. After such period, diminishing returns rapidly sets in, efficiency decreases, while time, and consequently expense and delay, increase.

Universal experience of trials very much longer than such a period is not only that they are longer than necessary for a fair and just determination of the proceedings, but that such trials are undesirable in themselves.

First, long trials place enormous strain on all participants - jury, defendants, the lawyers involved, the judge - and by imposing such strains threaten the performance of those participants in the closing stages of the trial.

Second, for defendants, the costs of an over-long trial are yet more expense, yet more delay and more strain, particularly as any evidence the defendant gives will be towards the end of the trial. Given the presumption of innocence, the trial should not be part of the punishment.

Third, over-long trials do not help the jury in their crucial fact finding role. Appellate courts both here and in America have been reluctant to set jury verdicts aside as being unsafe and unsatisfactory simply due to the length of trial in 
question. This is hardly surprising. Where the jury have reached a verdict properly open to them on the evidence, it would be a strong thing to say that such a verdict was unsafe and unsatisfactory where the outward and visible signs were that the jury had risen above the difficulties. But courts in both countries, when deciding or reviewing a question of severance, have been freer with their criticisms of long trials. Thus his Honour Judge Aspen in the District Court of Illinois when considering a 175 count indictment against 38 defendants in respect of over 150 factually separate criminal acts spanning a period of 20 years unsurprisingly decided that such a trial must be severed in to a number of less grandiose trials, and in so finding said this: 1

\begin{abstract}
"both common sense and scientific study dictate that as the volume of evidence and corresponding length of trial increases, the degree and quality of jury comprehension decreases proportionately. To expect any jury to accurately call and appraise the vast amount of detail and testimonial and documentary evidence I heard many months or even a year earlier is unrealistically optimistic."
\end{abstract}

To the same effect, but with one significant factual difference, in a case where the jury's civil verdict was set aside, in Mechanical and General Inventions Co. and Lehwess v. Austin and the Austin Motor Co. (otherwise known as the Sunshine Roof case), ${ }^{2}$ Viscount Sankey, LC, said this:

"I should be very loath to set aside any verdict of a jury arrived at after they had seen the witnesses and heard them. I cannot help thinking however, that in the present case, after a prolonged trial and thousands of questions in examination and cross-examination, it was impossible for the jury to have kept all the facts in their minds ... If the jury had the same advantages as we have had, in this long and complicated case, of having such a transcript of the evidence before them and the whole of the correspondence under their eyes, they could not have arrived at the conclusion that the licence agreement was made...

No jury properly directed could reasonably find that there was any such agreement and the verdict on this point must be set aside. In reaching this result I must not be thought to impugn the ability of the jury to come to a proper verdict, but rather to stress the difficulty of their task."

The difference was that here Viscount Sankey was speaking of a trial that took just 14 and a half days. Compare that with the recent Nottingham case where the 
jury sat for 253 days. The jury needs help, and we must see that they get it.

In these long trials it is essential that we offer juries the means of organising the mass of evidence they are confronted with. This means that they should be readily able to identify to what issue the evidence goes, to what issue the crossexamination is directed. Without that information, they will not be properly equipped to evaluate that evidence as it is given. It is not satisfactory for them to have to wait for an explanation of the potential significance of that issue in the summing up given perhaps months after the evidence has been heard.

Criminal trials should not be conducted in such a fog. To allow them to be so is to place an unfair handicap on the jury, to consign them, in the phrase of $\mathrm{Mr}$ Justice Berger of Canada, to "a judicial never-never land". Not, I think, J. M. Barrie's place, but the trackless wastes of the outback.

Even to-day, I am told that Assistant Recorders at the Judicial Studies Board (being taught the first elements of judging) are cautioned that (after the evidence and speeches but before summing up) it is prudent to check with the parties as to what the issues are. And this is in short trials. So what hope for the jury in long trials unless they go into those trials knowing just what the issues are, i.e. knowing what the defence will be? Why have they not routinely had this information already? The answer lies in the historical development of the adversarial system.

My criticism to date has not been of the working of the trial process in all serious fraud cases. But the satisfactory trial of such cases depends first on the consent of the defendant and his advisors to a fair but efficient trial, and second on a high degree of competence in both counsel appearing for him and appearing for the prosecution. Absent such consent and such competence, the system does not work as well as we are entitled to expect. We must have a system that does not depend on the defendant's consent and counsel's competence.

How have the problems arisen? As with so many things in this country, the problem stems from our history, and our early (and considerable) success. The two basic models for the criminal trial are the inquisitorial and the adversarial. In the former, the principal actors are the judge and the accused. In the latter, the judge retires to a less prominent position in the trial process and the lawyers for the parties dictate (within the flexible and subjective boundaries of relevance) the evidence that is called and the thoroughness with which it is examined; that is, they determine the size of the canvas, and the detail with which it is worked. So they determine the length of the trial, the cost of the trial, and indeed the delay caused to other trials in which they have no interest. Hence the fact that our system is open-ended, and our problems to-day.

The shift to the adversarial system occurred with us in the course of the 18th century with the coming of the lawyers into criminal trials. That was a good thing. Before the mid-19th century trials were nasty, brutish and short. But they were short.

Essential to the adversarial process was the oral tradition, the right to confront your accuser, to have your day in court. The perceived fairness of the system was 
widely recognised. John Mortimer was being more serious than his actual words might suggest when he listed the great British contributions to world civilisation as including the Plays of Shakespeare, the full breakfast, the herbaceous border, and the presumption of innocence. With the short trials of the day the system worked well. It still does, for short and simple trials - though there are fewer of them.

Many modern trials are not short - neither civil nor criminal. We live in a highly documented age. The photocopier and modern technology opens up endless potential for the reproduction, retrieval and electronic search for information in documents. In the current fashion in advocacy, detail reigns. Civil practitioners started the fashion. Criminal practitioners took it up. Your day in court was no longer enough. Now the claim often is to your year in court, or as long as you want, as long as you take. In some cases it is the prosecution that is to blame, in others the defence. In some cases trials are too long even though both parties regard themselves as keeping within both the letter and the spirit of the system. In others, the case is strung out, in an effort to play the system. In all cases it is effectively the parties who determine the length of a trial.

This is unsatisfactory. The system must not only be strong enough to be sure of defeating those who wish to frustrate and subvert the trial process. It must also be capable of eliminating all unjustifiable delay and expense, whether by an overelaborate prosecution or a defence which believes that their right is not simply to justice but to have the final word as to the time their trial may take, time enough for all hares to be raised, wild geese to be chased, and red herrings to be trailed.

This problem of the length of trials has grown considerably ever since the Roskill Committee was set up in 1984 with the following terms of reference:

"to consider in what ways the conduct of criminal proceedings in England and Wales arising from fraud can be improved and to consider what changes in existing law and procedure would be desirable to secure the just, expeditious and economical disposal of such proceedings".

That Committee reported in 1986. Many of its recommendations are to be found in the Criminal Justice Act 1987. I will call the Report and the Committee who produced it 'Roskill', and, accepting some further inaccuracy in the cause of convenience, the 1987 Act provisions as the 'Roskill' reforms.

For present purposes I can summarise the Committee's achievements as follows. It gave us a sophisticated and powerful prosecuting agency in the Serious Fraud Office. The abolition of committal proceedings was useful and has worked well in practice. It gave us the potentially vital procedure of the preparatory hearing; a procedure alas fatally flawed for lack of any real teeth, lacking as it does any effective sanction for non-cooperation. It improved the law of evidence. Overall it provided a legal framework within which, where the parties were agreed on any sensible short-cut, by and large the law did not get in their way. It leaves a system that enables the parties to secure "the just, expeditious and economical 
disposal" of serious fraud trials in those rare cases when all parties are agreed on all the desirable steps to that end, and where all parties are prepared to go far enough in that direction. What it does not do is to give the Court the powers it needs to ensure that the proceedings are justly, expeditiously, and economically disposed of when the parties do not so agree. The result is that to-day, post the Roskill reforms, the objectives of his terms of reference have still not been met.

I want to concentrate on two aspects in my examination of the Roskill reforms:

i) pre-trial disclosure of the defence;

ii) the question of admission of facts.

Roskill correctly identified one of the main weaknesses of the system as being the absence of a general requirement of pre-trial disclosure of the defence.

The right to withhold the defence until trial is one of the various aspects of the so called 'right to silence'. The absence of a general requirement of defence disclosure operates in Roskill's words, to make trials "longer, less efficient, more obscure, and ultimately less just." That is undoubtedly true, in every particular.

The objection in principle to defence disclosure is founded on the fact that the burden of proof lies on the prosecution. That objection had much greater force when prosecution disclosure of their case was less complete than it is now. In fraud cases a defendant used to have to wait for the opening before necessarily finding out exactly how the case against him was put. Particulars of the indictment were often refused on this ground. Full prosecution disclosure, made as a duty and not as a favour, is the necessary pre-condition to defence disclosure. And Roskill achieves this. This is done by way of the preparatory hearing provisions of the Criminal Justice Act 1987. The purpose of the preparatory hearing, as set out in section 7, is that of:-

(a) Identifying issues which are likely to be material to the verdict of the jury.

(b) Assisting their comprehension of any such issues.

(c) Expediting the proceedings before the jury; or

(d) Assisting the judge's management of the trial.

The trigger for any disclosure by the defendant is an order by the judge to the prosecution, under section $9(4)(\mathrm{A})$, to disclose:-

(i) The principal facts of the prosecution case.

(ii) The witnesses who will speak to those facts.

(iii) Any exhibits relevant to those facts.

(iv) Any proposition of law on which the prosecution proposes to rely.

(v) The consequences in relation to any of the counts in the indictment that appear to the prosecution flow from the matters stated in pursuance of sub-paragraphs (i) to (iv) above.

So by the time those orders have been complied with, total disclosure of the 
prosecution case will have been made to the defence, the witness statements and unused material presumably having already been disclosed. Then the judge may make an order under section 9(5) to the defence:-

(i) To give the court and the prosecution a statement in writing setting out in general terms the nature of his defence and indicating the principal matters on which he takes issue with the prosecution.

(ii) To give the Court and the prosecution notice of any objections that he has to the case statement.

(iii) To inform the court and the prosecution of any point of law (including a point as to the admissibility of evidence) which he wishes to take, and any authority on which he intends to rely for that purpose.

By that vital sub-section parliament has required defendants to make extensive pre-trial disclosure of their defence where such an order is made. That order is a legal obligation binding on the defence. It is statutory recognition of the fact that surprise is the enemy of justice. But in practice, on the post-Roskill experience, not every defendant has fully complied with such an order, and the reasons for this have been that the sanctions provided in the Act are inadequate to compel disclosure.

This is not the first time that Parliament has ordered defendants to disclose certain aspects of their defence before trial. Pre-trial disclosure of alibis was required by section 11 of the Criminal Justice Act 1967. Pre-trial disclosure of experts' reports is required by section 81 of the Police and Criminal Evidence Act 1984. In each of those cases the ultimate sanction is that the Court is empowered to refuse to allow the defence to call such evidence unless prior disclosure has been made. This ultimate deterrent is seldom used. One can imagine the difficulties if a defendant went into the witness box and said that he would like to tell the jury where he was at the time of the crime but the judge would not let him. But even if the ultimate sanction is seldom used, it seems to me that it is desirable where there is an order for defence disclosure that such a sanction is present. And none is given by the Act. The only express sanction is that set out in section 10(1) of the Act.

Section 10(1) provides that any party can depart from the case he disclosed at the hearing. The sanction: comment. Comment comes late: in the final speeches and the summing up. Comment, which must be fair, can only be effective if the suggestion can credibly be made that the lateness of the disclosure suggest the defence to be false; that is, fabricated after the date for disclosure, a document forged, or a story made up. But often non-disclosure points to tactics and not veracity, an attempt to obtain the now illegitimate advantage of surprise. The truth often is that the defendant would prefer not to disclose his defence than disclose and give the prosecution the time to investigate and deal properly with his defence. So the judge's right to comment is not feared as a sanction, and in practice compliance with the Court's order is treated as being voluntary by the defence. If 
it suits their tactical book, they disclose, if not, they do not.

This is unsatisfactory. It is the law of the land that the defendant shall disclose his defence. In choosing to keep it up his sleeve he is breaking that law in disobeying the order of the Court. Such a breach is punishable as a contempt. But the Court will naturally not want to go down that route, either before or after trial. So the Court and the law are flouted.

The second weakness in the order for disclosure of the defence is that section 10 (3) provides that if there is no departure from the case statement, then neither it nor any information relating to the defence case given in the preparatory hearing may be disclosed to the jury without the defendant's consent. This provision also presumably stems from the burden of proof; the fact that the defence can sit back and see whether the prosecution can prove their case. But its effect is damaging in two ways; first, it prevents the jury knowing from the beginning of the trial what the issues are (unless all defendants consent) and second, because of this an immediate incentive towards proper defence compliance is lost, and so the Court is told less than otherwise might be the case.

As the law obliges the defendant to disclose his case, how can we achieve compliance with the law? The best answer lies in securing the defence's full cooperation with a fair, orderly and efficient jury trial. And that cooperation is best achieved if there is some advantage (or avoidance or mitigation of disadvantage) in compliance. I return to this later. The present position is unsatisfactory. We need statutory reform of section 10 .

I examine next the admission of facts under Roskill. Where the prosecution have served the defence with notice of documents the truth of the contents of which in their view ought to be admitted, the Court may order the defendant to serve a notice to say whether he agrees and admits those facts, and if not the reason for any disagreement. The Act unsurprisingly gives the Court no power to order the defence to agree even the most obviously incontrovertible fact. This is a natural consequence of the burden of proof. But the defence has to tell the Court its reason for not admitting those facts. The real reason often is that no disadvantage is seen in not admitting the indisputable, and the hope is that something will turn up.

Let us examine a classic example: the path money took after flowing through many bank accounts in many countries. I am told that in a recent fraud trial in Hong Kong, three months was spent calling such evidence without a single challenge to it being thrown up in cross-examination.

The burden of proof, of course, entitles the defence to put the prosecution to proof of their case. But at what cost? And to what point? In such cases there should be power to tell the jury why that evidence had to be called. It would lead to realistic admissions. But section $10(3)$ prevents it.

What incentives can be given to persuade the defence to make the admissions? If the burden of proof is to remain inviolate in all respects and in all circumstances, the answer is none whatsoever. The result will be that whenever any defendant sees possible advantage in spinning out the process he can do just that. Why should 
he want to do this? If an unscrupulous defendant believes that the criminal justice system can be defeated by unnecessary complications, delay, general obfuscation or perhaps even by provoking a jury mutiny, then he may resort to such tactics. They seldom work. But such tactics are used and they are very expensive.

Now, of course, if every defendant was entitled to his year in court, or as long as he liked, there would be no point in raising points of cost-effectiveness in relation either to non-admission of facts or the length of speculative cross-examination. The system would (up to the limit of abuse of process of the Court) be open-ended, and would be proud of it. The argument would be that justice requires no less. In days of predominantly short trials, protected from the logical extremities of the system by the competence of counsel and the general consent of the accused to a proper trial under the process, the open-endedness of the system was not a problem or indeed a source of comment.

With the mega-trial, and a greater public awareness of the political necessity of budgetary restraints, it seems that those days are over. Budgets being finite, public money ineffectively spent on one defendant's prosecution or defence is likely to be made at the expense of necessary expenditure skimped in another case. How can limits be imposed? The objectives must be to have shorter, cheaper and more efficient trials without paying a penalty in fairness. And we do not have the answer at the moment, even after Roskill.

Before I pass from the Roskill reforms in the 1987 Act let me say this. In the orders for pre-trial disclosure of the Defence we have a powerful weapon towards shorter and better focused trials. But that weapon cannot be properly used until that information can be shared with the jury - and shared with them from the beginning of the trial. And for so long as that information cannot be shared with the jury, and while there is no effective sanction against non-compliance, prosecution and judges will be discouraged from fully exploiting those preparatory hearing powers. My advice to trial judges is to ignore their ultimate lack of teeth and to insist on full compliance with the orders made, returning all inadequate documents to be done again, and insisting on proper and truthful reasons for the non-admission of the apparently unchallengeable.

Next, what are the judge's powers to reduce the length of serious fraud trials?

Basically, the judge has one very powerful weapon against long trials, and when that has been used, his powers over the length of the case are negligible.

The first line of defence against such over-long trials is the remedy of severance: namely to split what, in the absence of trial management difficulties of the sort mentioned above, would ideally be one long trial into a number of shorter ones. Such a split may be as between defendants, or as between incidents. Where the right split cannot be agreed between the parties, the question comes before the trial judge to decide. It should not be thought that defendants always opt for severance, while the prosecution wants a mega-trial. That is not always so. It was not so in Guinness 1 for example where the defendants all wanted a mega-trial. I ruled against them on the basis that such a trial would have been unmanageable 
and I am confident that that was the right decision. But the disadvantages of that course are also patent. It is useful to set out the down-side of severance.

First, the second and any subsequent trial will usually have to wait not only for the conclusion of the first trial, but (on the experience of serious fraud cases) for the conclusion of any appeals relating to the first trial. So severance keeps matters hanging over later defendants for an unacceptably long time.

Second, severance can lead to the possibility of inconsistent results, perhaps reflecting different juries different views on the credibility of an essential witness common to both trials. It is clearly desirable for such a potentiality to be avoided.

Third, there may be the danger that justice is not done because the criminal picture is never seen as a whole, and a partial version of it may prove to be misleading.

Fourth, where the severance relates to counts in the indictment rather than to actual defendants, the public perception is that it is unattractive to have a second trial of the same person arising out of the same series of criminal acts - and it is unattractive whether the first trial ended in his conviction or in his acquittal.

Fifth, severance may increase the strain on and inconvenience for witnesses who have to give essentially the same contentious evidence more than once.

Sixth, severance may give rise to fears that the publicity given to the proceedings and result of trial 1 may impact on trial 2.

In the main, our courts, when having to choose between the devil of severance and the deep blue sea of an over-long trial have generally preferred the former, stating that only the criterion of absolute necessity justifies the latter. But severance cannot be a wholly satisfactory answer while it brings its own undesirable side effects as illustrated, and also, even after the 'right' severance, you may still have trials that turn out to be too long - particularly when the defendant has not disclosed his defence in advance, and so that defence cannot be properly evaluated. Therefore, severance should not be applied as a poultice to an unsatisfactory trial process. If the trial process is unsatisfactory, we should reform it, and only then use severance as a weapon of control.

And apart from severance, the trial judge's other powers are not effective to shorten trials sufficiently. I deal with a number of suggestions.

One remedy often suggested is to blame the current length of trials on an overloaded indictment. At its least sophisticated, this criticism focuses on the number of counts in the indictment. It is the factual content of the trial and the detail with which it is examined that lengthens matters, not ultimately the number of counts in the indictment. After the 'right' severance, it is unreal to suppose that all further problems can be solved simply by telling the prosecution to reduce the number of counts. Everyone agrees on the desirability of the 'lean and mean' indictment. But even such an indictment will still leave you with cases that are still capable, under the present system, of being much too long. The overloaded indictment and the over-enthusiastic prosecutor have thrown up some problems, but they have been responsible for a minority of them. It is the factual content of 
the trial and the detail with which it is examined that lengthens matters, not ultimately the shape of the indictment.

Sometimes it is suggested that absolute offences should be used by prosecutors. In serious fraud cases, an almost universal ingredient in any count is dishonesty. The allegation of dishonesty greatly widens the potential scope of the trial. It will often require the Court to examine other transactions and the reports of them that may or may not have contributed a belief that what was done was honest. And so the allegation of dishonesty widens and lengthens the scope of the trial.

Accordingly, one suggestion made to shorten trials is to use absolute offences. There are examples in the legislation, and more could be added. They are there, they can be used. But to be prosecuted in a serious fraud matter is so serious for the defendant that these prosecutions should essentially be reserved for cases of dishonesty. Where the major players have been dishonest, that is what they should be charged with.

Next, the trial judge's power to decide (as a matter of law) what is relevant. This is a notoriously imprecise concept. In A. G. v. Hitchcock ${ }^{3}$ in 1847 Lord Rolfe said this:

"if we lived for 1000 years instead of about 60 or 70 and every case was of sufficient importance, it might be possible and perhaps proper . . . to raise every possible inquiry as to the truth of statements made... In fact mankind finds it impossible."

Or as Justice Holmes more pithily put it from across the Atlantic: the line of relevance is drawn as "a concession to the shortness of life."

Where that line is drawn is a question decided on a mixture of logic and experience. With full disclosure of the defendants case, the trial judge would be able to draw the line more accurately. But where honesty is the issue, it is unrealistic to look to this power to solve the problems of long trials. And once the line of relevance has been drawn, the judge has but a limited discretion to exclude relevant and admissible prosecution evidence, but no discretion to exclude relevant and admissible defence evidence. So the judge's powers to cut down on the evidence called are severely limited.

I examine next his power to shorten cross-examination. Lord Wright had this to say:

"Now cross-examination is one of the most important processes for the elucidation of the facts of a case, and all reasonable latitude should be allowed, but the judge always has a discretion as to how far it may go, or how long it may continue. A fair and reasonable exercise of his discretion will not generally be questioned by an appellate court."4 
The guillotine limiting cross-examination was used in the extreme case of Morley, ${ }^{5}$ where the opening took six minutes, the evidence in chief of the prosecution witness took one hour and yet the trial (the defendant was in person) took 38 days, and only ended as soon as it did because his removal from court on the judge's direction prevented him from making a closing speech.

But it is not altogether clear from the authorities whether that power is based on the Court's discretion to prevent an abuse of process or whether some lesser test could justify intervention. In this, as in other respects, the basis and the extent of the judge's discretion to control the trial process have never been spelt out.

Lastly, in relation to the judge's powers, there is what Rosemary Pattenden in her useful work fudicial Discretion and Criminal Litigation refers to as the judge's "moral authority" to discourage or persuade advocates from unduly lengthening trials - the Barbara Woodhouse school of court control, based on the power of the human eye and some judicious impatience. Some advocates are more susceptible to that moral pressure than others. And judges should be able to apply rules rather than show impatience. The good judge is the patient judge. Impatience should not have to be part of the efficient judge's weaponry.

Such then are the judge's present powers. They are not sufficient to enable him significantly to curb the tremendous amount of wasted time that occurs in long trials.

Huxley, under the influence of mescalin, when asked about time, said "There seems plenty of it." Such is the happy state of counsel in a long trial. Somehow it must be rationed. Perhaps a start would be to give the judge specific powers to do so, coupled with an express duty to use those powers to secure as short a trial as is consistent with fairness. Perhaps we could look to rule 403 of the American Federal Rules of Evidence which states: "Although relevant, evidence may be excluded if its probative value is substantially outweighed by the danger of unfair prejudice, confusion of the issue, or misleading the jury, or by considerations of undue delay, waste of time, or needless presentation of cumulative evidence." This is reinforced by rule 102, requiring the trial judge, while securing fairness, "to eliminate unjustifiable expense and delay to the end that the truth may be ascertained and the proceedings justly determined."

So presently the judge has no clear repository of powers which would enable him by order rather than persuasion significantly to shorten the trial process before him. The basis for justifying his discretionary powers of intervention are not entirely clear - they may merely be his power to prevent an abuse of process by the Court, and such a power can only be used in extreme circumstances.

Therefore, under our system as it exists at present, I believe that the parties and not the Court will continue to retain control over the length a case takes, and so the system will remain open-ended, and unsatisfactory for that reason. Without 
legislative changes, I do not believe that things will get better. In fact I am certain that they will get worse. There is a technical reason for this. The provisions of the Criminal Evidence Act 1988, giving the judge powers to turn documentary hearsay into primary evidence, means that the defence will now have available wide powers of subpoena to obtain documents. Previously such attempts were usually defeated by the restrictive decision of $R$. v. Cheltenham f ustices, Ex Parte Secretary of State for Trade 6 on the basis that the subpoena only operated on evidence, and the documents sought were not and could not be primary evidence. Now that they are capable, by order of the Court, of becoming primary evidence under the provisions of the Criminal Justice Act 1988 many such documents wil become available to the defence, and so we can look forward to trials with more documents rather than fewer. I should make it clear that I welcome what I take to be the demise of the Cheltenham Justices decision. Under it defendants were denied sight of documents in possession of third parties which might well have assisted them in their defence. But trials will get longer as a result.

This pessimistic analysis brings me to the call to dispense with juries in these trials. Many (but not all) of the problems of trial management $I$ have highlighted would be reduced or avoided if trial were by judge alone or judge sitting with assessors. Civil justice shows that we would still have very long trials, but they would be more easily manageable, and less vulnerable to the various vicissitudes that hit long trials.

Consequently the jury is under some threat, though I believe less than at one time. Roskill recommended the replacement of the jury in certain categories of long and complex fraud cases. With trials now routinely going months and sometimes exceeding a year, the problem of jury concentration and comprehension increases.

Clearly there is force in those criticisms. But the great majority of judges who have tried long frauds have come through such trials confident in their jury, and in the verdicts they would give. The jury as a whole is, by some human chemistry, greater than the sum of its parts, and their conscientiousness and concentration impressive.

I believe we should keep the jury for the following reasons. First, we must have equal justice for white collar fraud as for blue. Fundamental to the concept of one and the same justice for all is trial by jury. It is sometimes suggested, often by City sophisticates, that the self-proclaimed complexity of their business dealings can only be understood by fellow initiates. You will remember 1066 and All That: "Barons should be tried by other Barons, who would understand."

I reject that view. The jury inject a crucial democratic element of trial by the people into our penal system. These cases are about honesty, and the jury should be the judge of that, applying the same standards of honesty to commercial fraud as social security fraud. And jury verdicts are, in the vast majority of cases, 
accepted - even in this questioning and undeferential age. This is as important for the acceptability of acquittals as it is for the acceptability of convictions. The potential critic of any verdict will of course know little of the facts of the case, though they will not be inhibited by that. And after trial the Roskill tribunal's verdict would be open to the saloon-bar cynic's allegation that an acquittal is simply the Establishment looking after its own, or a conviction reinforcement of the defendant's claim that he was the Establishment's pre-determined scape-goat. But a jury's verdict silences such suggestions.

There seems to me to be an even more fundamental reason for not doing away with the jury at this stage in the development of the criminal adversarial system. And that is that as the system has moved from short trials to long trials, conducting both by the same procedures, so it has not adapted to give the jury the additional help and support they need in long trials. And until we have seen what they can do with proper help and support it must be wrong to call for their abandonment in difficult cases. A body of such constitutional importance that has served us so well simply cannot be jettisoned before it has been given its best chance of working in long trials.

I do not run away from the fact that the presence of a jury lengthens trials considerably - especially where a study of documents is involved. Section 69 of the Supreme Court Act 1981 recognises this in civil matters. A judge (sitting with or without assessors) can read the documents out of court, and so they can be taken as read at the trial. The jury must be taken laboriously through them, absent prior discussion and agreement as to a summary of their content.

Documents are not the only reason why a trial by jury will always be longer. You must have shorter hours in the trial day, and more frequent breaks. You have counsel proceeding at what they (often wrongly) take to be the speed of the slowest ship. You cannot attempt to move them on as soon. You get points taken which are simply too bad to be taken before a judge. You get posturing and attempted obfuscation. The judge will be more reluctant to rule evidence irrelevant and may allow more time on matters of marginal relevance. In other words, you give more scope for defendants trying to play the system.

But until all acceptable measures have been taken to shorten the jury trial, it is wrong to call for its abolition in certain categories of case.

What I want to be able to do is to give the jury the help they need. To this end I want to know what the defence case is before the trial starts. I want to be able to tell the jury what the issues are before the trial starts - making clear of course that any such list is subject to change and the unexpected.

I would like to say a word at this stage about the traditional opening to the jury trial; namely when the jury are sworn in and immediately the prosecution rise to open their case. I regard this, from the Court's point of view, as unsatisfactory. I believe, in common with at present a small but growing minority of judges here (and more in other jurisdictions), in addressing the jury before the prosecution does. I explain to the jury (my novice fellow judges) our respective roles in the 
trial. I explain the shape of the trial, and how they can best approach their task. I tell them of the burden and standard of proof. More and more judges, in this and other common law jurisdictions, are doing this. But I would like to go further. If the judge rather than the prosecution were to open the issues to the jury, I believe that defence compliance with the disclosure orders will be much fuller than if they fear that the prosecution will use the opening to poison the well.

At present there is little comfort in the opening of the trial for the defence. The prosecution open their case, often with head-line catching comment, and the defence has no opportunity to say what their answer is. In short and simple cases this does not matter; the issues are clear and self-evident. In long fraud cases it may matter. It seems to me that there is a case for the trial judge opening both the law and the issues to the jury. First (and I would imagine non-controversially), I would like to give them in writing the directions of law as to the ingredients of each offence charged, for them to have by them to consult at will. Next I would like to open the issues to them. This would require summarising each defendant's case. Where he, in his defence case statement, has advanced no positive case, then the jury of course will be told that. They will be told that this is his privilege. I would envisage giving them a list of issues, relating to each defendant and each count, and inviting them to refer to that list when wondering to what issue the crossexamination goes.

I believe that such a course will have the following benefits:-

i) It will help the jury. It will help them to judge the importance of the evidence, and so the better to evaluate it and retain it in their memories.

ii) It will help the judge control the case. Where there are listed issues, the question "to what issue does this go" requires a direct answer, in a way that, where the issues have not been defined, "what is the relevance of this line" does not.

iii) It will tend to either encourage or compel proper defence disclosure. Encourage, because if your defence is going to be put before the jury in the identification of the issues you will want to ensure that the Court does it justice. Compel, because then where there is a departure, it will be clear to the jury, with the likely reason for it. Where the departure is caused by an unexpected turn in the evidence, they will understand. Where it is caused by flagrant concealment, they will form their own conclusions. I believe it would encourage full disclosure.

I should also like to make available to them and the parties, daily or weekly, my running summaries of the evidence on each issue, with suitable warning as to reserving judgment until the evidence was complete.

In short, I want to give them all the help that I can; first, to ensure that they are in a position to appreciate the relevance and significance of each bit of evidence or line of cross-examination as it is given, and secondly, so that they should have available for use if they wish it, a brief summary of the up-to-date state of the evidence on each issue as the trial proceeds, and not have to wait for the summing 
up before the first such assistance is given to them.

So I would retain the jury but make sure the system gives them more help. In some jurisdictions, the defendant can elect to dispense with trial by jury. That right does not seem to be much used. If such a rule were introduced here, I would like to consider whether the choice should be subject to the leave of the Court. I can imagine circumstances where I might feel that, notwithstanding the defence preferences, trial by jury was the only right mode of trial.

If the trial judge is allowed to use knowledge obtained through defence disclosure at the preparatory hearing to compile a list of issues (to be updated as necessary) to put before the jury, and if as I believe he already may be, he may properly keep the jury abreast of the evidence in outline given on each issue by making available to them the embryo of what will eventually be his summing up, that will go some way to meeting one of the major criticisms of certain serious fraud trials, namely that they are insufficiently focused.

I believe these proposals (and all that goes with them, i.e. fuller defence disclosure than we get to-day) will do something to reduce the length of these trials. However I am far from confident that it will do enough, certainly not enough to reduce trials to my suggested maximum length of four months for all save exceptional trials.

If it is desired to ensure that the 'normal' serious fraud trial is concluded within such a period, I believe that can only be done with time limits. This idea of 'capped' justice, is of course, anathema to our system. Jury trials subject to such time limits have been held in America, though not yet criminal trials. Long anti-trust trials have been subject to this discipline. From the reports I have heard, lawyers for the parties greatly disliked the idea in prospect, but were pleasantly surprised at how well it worked. Time was rationed, and measured by chess clocks. As time was thus demonstrably finite, the parties' deployment of their time pointed what they regarded as the essentials of their case - to the benefit, I would have thought of all and especially the jury. I cannot yet imagine that happening in a criminal trial here, or at any rate not until such a system has been thoroughly tried elsewhere.

In civil courts too the timeless-test nature of trials is causing some concern. In Ashmore v. Corporation of Lloyd's ${ }^{7}$ the trial judge wanted to decide some preliminary questions of law which might have determined or greatly shortened the action. The plaintiffs wished to have their evidence heard before the points of law were decided. The Court of Appeal agreed with the plaintiffs. On appeal to the House of Lords, Lord Roskill said this: ${ }^{8}$

"The Court of Appeal appear to have taken the view that the plaintiffs were entitled of right to have their case tried to conclusion in such manner as they thought fit and if necessary after all the evidence on both sides had been

7. [1992] l W.L.R. 446.

8. At p. 448 . 
adduced. With great respect, like my noble and learned friend, I emphatically disagree. In the Commercial Court and indeed in any trial court it is the trial judge who has control of the proceedings. It is part of his duty to identify the crucial issues and see they are tried as expeditiously and as inexpensively as possible. It is the duty of the advisers of the parties to assist the trial judge in carrying out his duty. Litigants are not entitled to the uncontrolled use of a trial judge's time. Other litigants await their turn. Litigants are only entitled to so much of the trial judge's time as is necessary for the proper determination of the relevant issues."

\section{Lord Templeman said this: ${ }^{9}$}

"Mr Lyndon-Stanford repeated the arguments in the Court of Appeal and, as Ralph Gibson LJ remarked: 'He claimed in particular that it was wrong to take the conduct of the proceedings out of the hands of the plaintiffs and thereby to disappoint the plaintiffs in their legitimate expectation that the trial would proceed to a conclusion upon the evidence to be adduced.' Ralph Gibson LJ thought that there was 'considerable force in these submissions'. My Lords, I disagree; the control of the proceedings rests with the judge and not the plaintiffs. An expectation that the trial would proceed to a conclusion upon the evidence to be adduced is not a legitimate expectation. The only legitimate expectation of any plaintiff is to receive justice."

Might not that be the beginning of the end of open-ended litigation?

If, as I believe, there is a general consensus that present criminal fraud trials are longer (and consequently costlier) than the combined imperatives of the fair trial and the just result require, time limits will have to be examined at some point. So, using a lecturer's licence to be provocative, might I ask you to contemplate the unthinkable? Might not there be a statutory limit on the length of jury trials, only to be exceeded with leave of the Court? Might not the Court be given specific statutory powers to ensure that jury trials are tried as expeditiously as fairness permits, and be enjoined to use those powers to ensure that the trial limit is kept to? Might not Parliament give the Court power to deny jury trial to a defendant if satisfied that the case cannot be brought within the statutory time limits only because of unreasonable refusal by the defendant to admit facts which plainly should be admitted.

Well, like you all, I rather doubt it. But equally do you imagine that our criminal justice system will continue to be open-ended as to time and consequently as to expense for ever? And if you can't imagine our system remaining as it is, won't something like that have to happen? 